Supporting Information

\title{
Inclusion of Amine Isomers with Open-Chain Hosts Having a Partial Structure of $p$-tert-Butylthiacalixarene
}

\author{
Ikuko Miyoshi, Hayato Sonehara, Jun Ogihara, Tomoaki Matsumoto, Naoya Morohashi, \\ and Tetsutaro Hattori ${ }^{*}$ \\ Department of Biomolecular Engineering, Graduate School of Engineering, Tohoku University, \\ 6-6-11 Aramaki-Aoba, Aoba-ku, Sendai 980-8579, Japan
}

\section{Contents:}

Powder X-ray diffraction (PXRD) analysis of inclusion crystals $\mathrm{S} 2$

Crystal structure of 2.6-methylquinoline-acetonitrile S3

Crystal structure of 2·(trans-4-methylcyclohexanamine) 3

Crystallographic data for inclusion crystals S8

Thermal ellipsoid plots of inclusion crystals 


\section{Powder X-ray diffraction (PXRD) analysis of inclusion crystals}

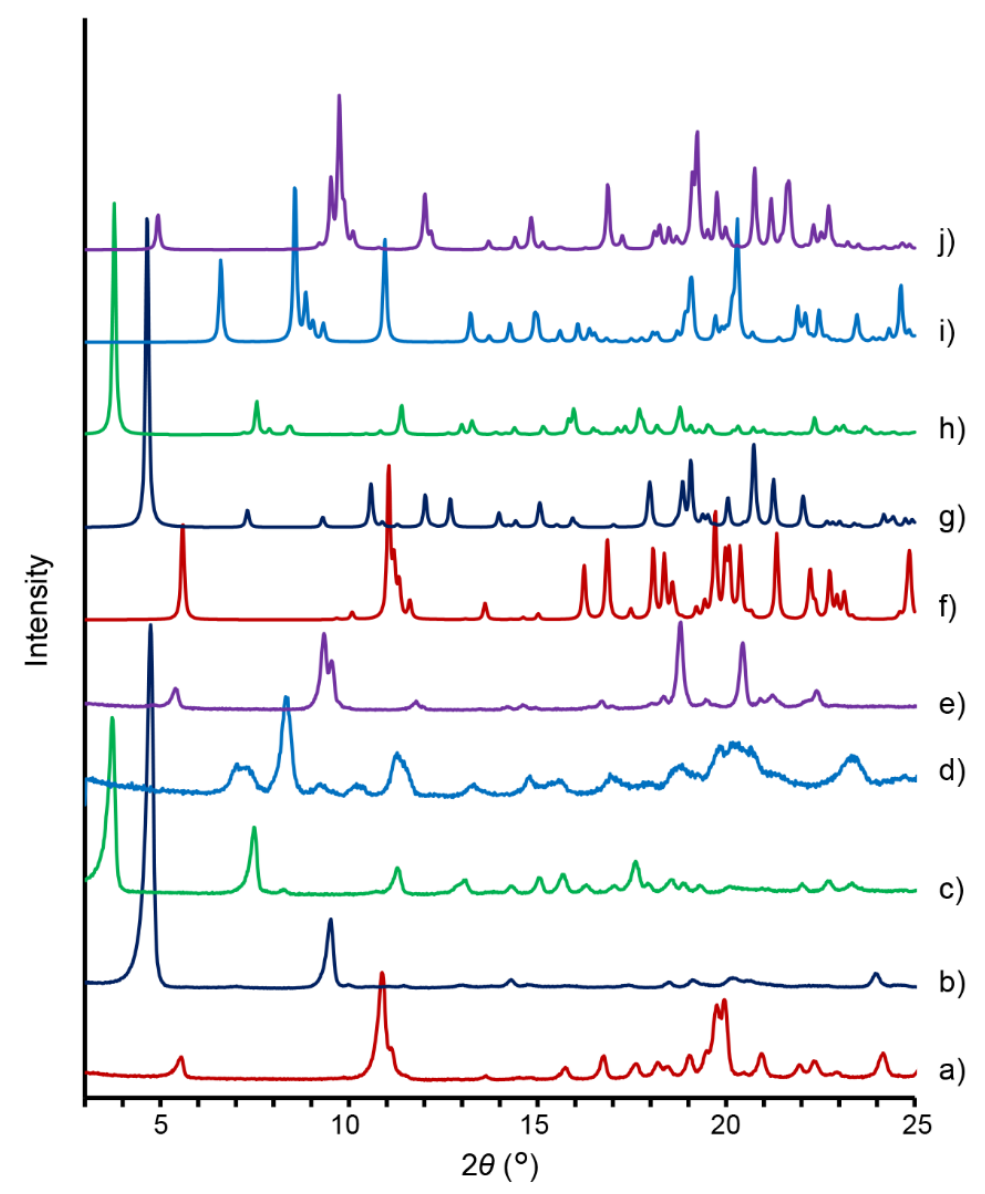

Figure S1. Comparison of the PXRD patterns of inclusion crystals prepared by inclusion experiments using single guest amines with those simulated from single-crystal XRD data for the corresponding single crystals: PXRD patterns measured for the inclusion crystals of diacid 2 with (a) 3-methylpyridine, (b) 4methylpyridine, (c) 2-methylquinoline, and (d) 6-methylquinoline and the inclusion crystal of monoester 3 with (e) trans-4-methylcyclohexanamine. PXRD patterns simulated from the single-crystal XRD data of (f) 2·3-methylpyridine, (g) 2·4-methylpyridine-toluene 0.5 , (h) 2·2-methylquinoline-toluene 0.5 , (i) 2·6methylquinoline toluene, and (j) 3·trans-4-methylcyclohexanamine. 


\section{Crystal structure of 2·6-methylquinoline-acetonitrile}

Single crystal $2 \cdot 6$-methylquinoline acetonitrile was prepared by leaving a solution containing diacid $\mathbf{2}$ (3.0 $\mathrm{mg}, 6.72 \mu \mathrm{mol})$ and 6-methylquinoline $(1.6 \mathrm{mg}, 16.8 \mu \mathrm{mol})$ in acetonitrile $(1 \mathrm{~mL})$ at room temperature. The crystal belongs to the triclinic system with the $P \overline{1}$ space group $(\mathrm{Z}=2)$. Diacid 2 forms a 1:1 salt with 6-methylquinoline (Figure S2a). Two 1:1 salts related by an inversion center are gathered to form a 2:2 self-inclusion complex so as to include each other's phenol units in their concaves (Figure S2b); a couple of complementary $\mathrm{CH}-\pi$ interactions are observed between a tert-butyl group of one host and a benzene ring of the other and vice versa. Two adjacent self-inclusion complexes are connected through a couple of complementary hydrogen bonds between carboxy and carboxylato groups, thereby forming an infinite columnar structure along the $b$-axis (Figure S2c). The columnar structures are arranged along the $c$-axis to form a layer parallel to the $b-c$ plane; between adjacent columnar structures, a $\pi-\pi$ interaction and two hydrogen bonds are observed between each amine molecule in one column and a neighboring host molecule in the other column and vice versa. The layer piles up along the $a$-axis in such a way that amine molecules in the upper and lower layers are stacked alternately along the $b$-axis (Figure S2d); between adjacent layers, each amine molecule is connected to a neighboring host molecule through a $\mathrm{CH}-\pi$ interaction and a hydrogen bond. Between adjacent layers, there are disconnected spatial voids, each of which is filled with two acetonitrile molecules, thereby realizing tight packing; the crystal density is 1.248 $\mathrm{g} / \mathrm{cm}^{3}$. 
a)
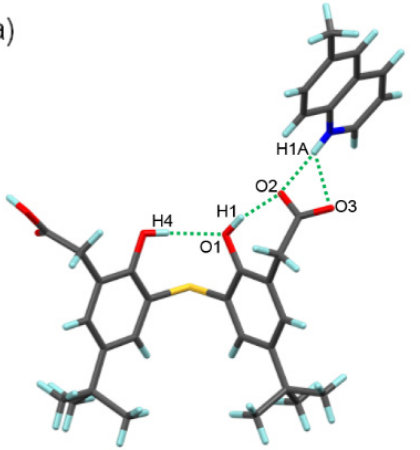

b)

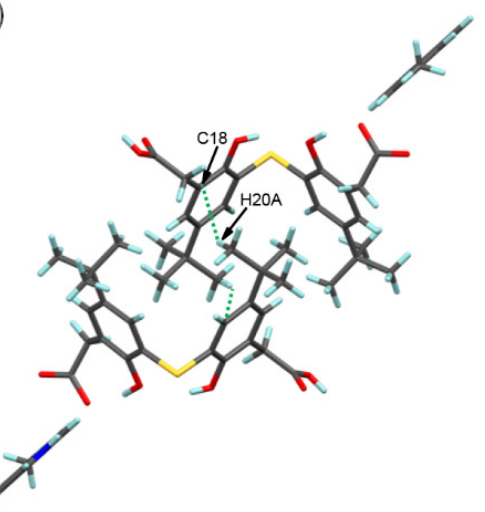

c)

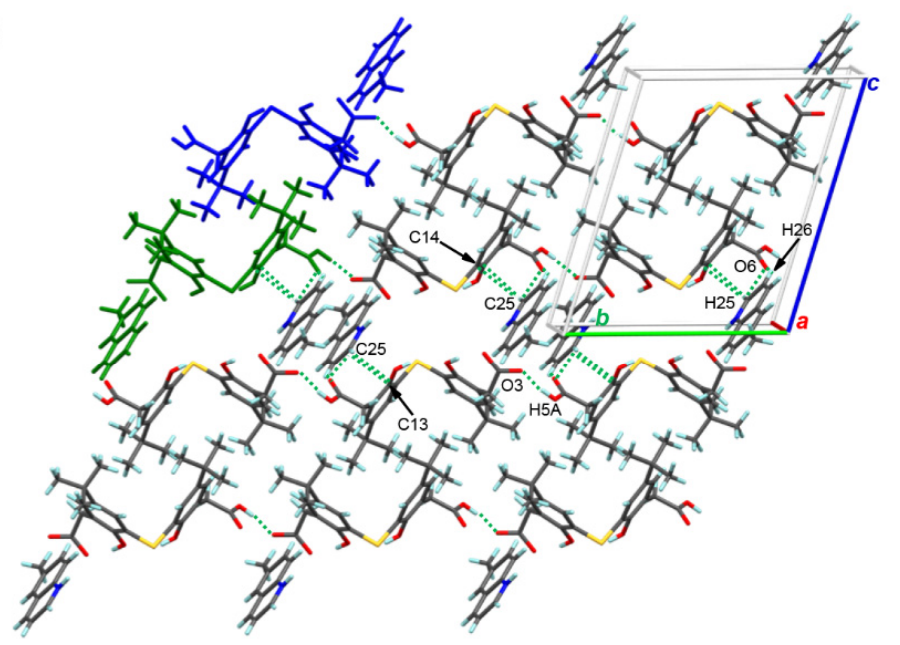

d)

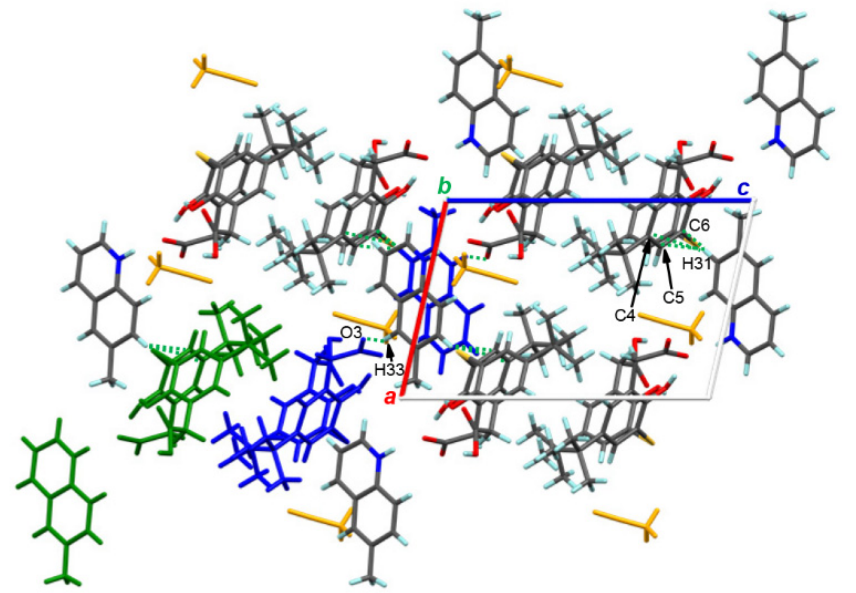

Figure S2. X-ray structure of 2-6-methylquinoline-acetonitrile: (a) a 1:1 salt between 2 and 6-methylquinoline, (b) a 2:2 selfinclusion complex, (c) a parallel cross-section to the $b-c$ plane, and (d) a parallel cross-section to the $a-c$ plane. In (c) and (d), a pair of 1:1 salts are color-corded. In (d), solvent molecules are colored orange and interactions from solvent molecules are

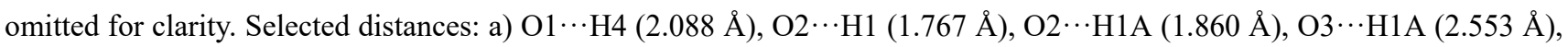
b) $\mathrm{C} 18 \cdots \mathrm{H} 20 \mathrm{~A}(2.886 \AA)$, c) O3 $\cdots \mathrm{H} 5 \mathrm{~A}(1.734 \AA), \mathrm{C} 13 \cdots \mathrm{C} 25(3.134 \AA), \mathrm{C} 14 \cdots \mathrm{C} 25(3.246 \AA), \mathrm{O} 6 \cdots \mathrm{H} 25(2.487 \AA), \mathrm{O} 6 \cdots \mathrm{H} 26$ (2.628 $\AA$ ). d) $\mathrm{C} 4 \cdots \mathrm{H} 31(2.876 \AA), \mathrm{C} 5 \cdots \mathrm{H} 31(2.734 \AA), \mathrm{C} 6 \cdots \mathrm{H} 31(2.771 \AA), \mathrm{O} 3 \cdots \mathrm{H} 33(2.598 \AA)$. 


\section{Crystal structure of $2 \cdot($ trans-4-methylcyclohexanamine) 3}

Single crystal $\mathbf{2} \cdot($ trans -4 -methylcyclohexaneamine) 3 was prepared by leaving a solution containing monoester $3(2.0 \mathrm{mg}, 4.48 \mu \mathrm{mol})$ and trans-4-cyclohexanamine $(30.4 \mathrm{mg}, 0.269 \mathrm{mmol})$ in benzene $(2 \mathrm{~mL})$ at $30{ }^{\circ} \mathrm{C}$. The crystal belongs to the triclinic system with the $P \overline{1}$ space group $(\mathrm{Z}=2)$. In the crystal, diacid 2 with a syn conformation forms a 1:3 salt with three amine molecules using the two carboxy groups and a hydroxy group (Figure S3a). One of the amine molecules connected with a carboxyl group (amine A) is embedded in the concave of the host molecule, while the other two amine molecules connected with another carboxy group (amine B) and a hydroxy group (amine C) are placed outside the cavity; the inclusion of amine A is stabilized by a hydrogen bond between its ammonio group and another hydroxy group and a $\mathrm{CH}-\pi$ interaction between its methylene hydrogen at the 2-position [6-position] and a benzene ring. Two 1:3 salts related by an inversion center are connected through two couples of complementary hydrogen bonds between the ammonio groups of amines A and B in one 1:3 salt and the two carboxylato groups in the other 1:3 salt and vice versa, thereby forming a 2:6 inclusion complex (Figure S3b); a couple of complementary hydrogen bonds are also observed between methylene hydrogens at the 6-position [2position] of amine A and carboxylato groups. Two adjacent 2:6 inclusion complexes are connected through a couple of complementary hydrogen bonds between the ammonio groups of amine B and the carboxylato groups paired with amine $\mathrm{A}$, thereby forming an infinite columnar structure along the $b$-axis (Figures S3c and S4). The columnar structures are arranged along the $a$-axis to form a layer parallel to the $a-b$ plane. Each molecule of amine $\mathrm{C}$ tightly connects two adjacent columns through hydrogen bonds between its ammonio group and two carboxylato groups paired with amine A and amine B in different 2:6 complexes and $\mathrm{CH}-\pi$ interactions between its hydrogen atoms at the 2- and 4-positions and a benzene ring; between adjacent columns, $\mathrm{CH}-\mathrm{S}$ interactions are also observed between hydrogen atoms of amine $\mathrm{A}$ at the 5position [3-position] and a sulfur atom. The layer piles up along the $c$-axis (Figure S3d). There are no spatial voids in the crystal. 

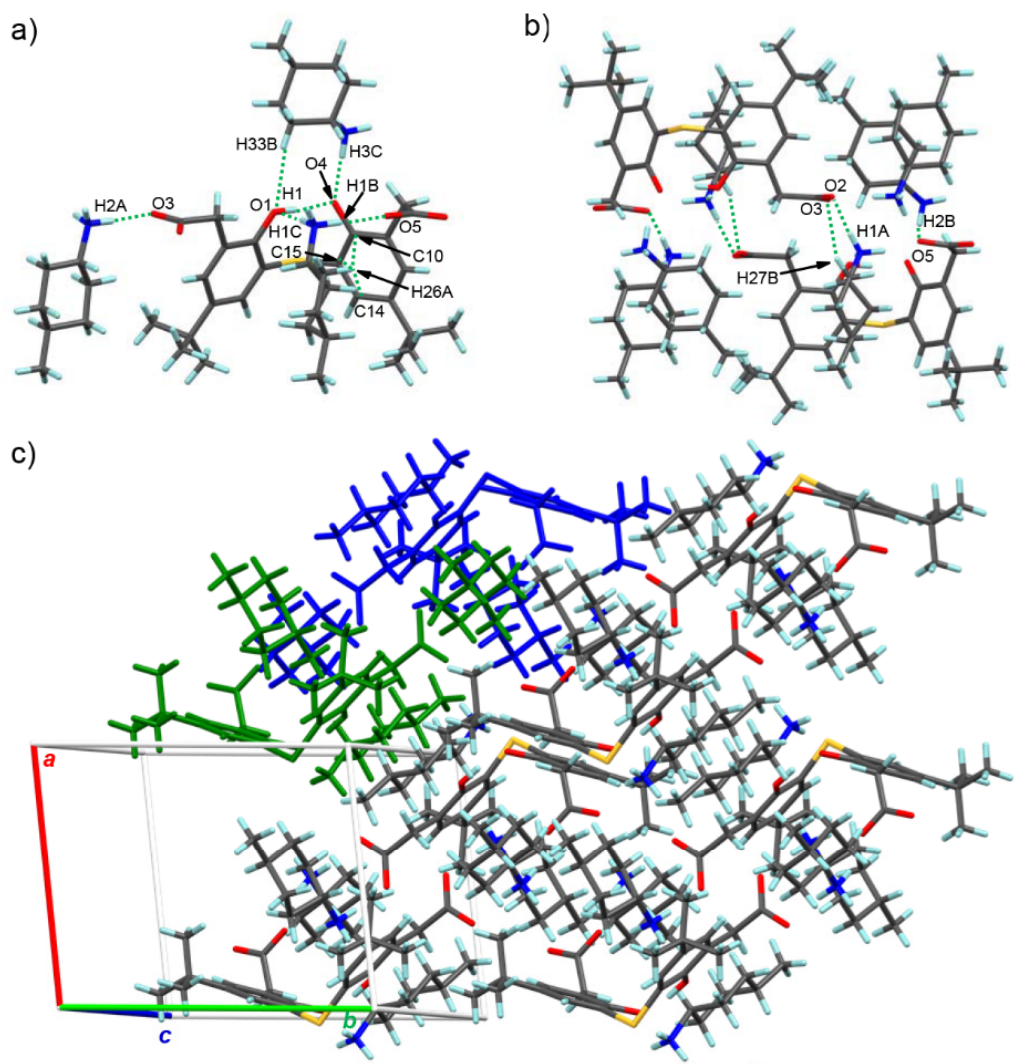

d)

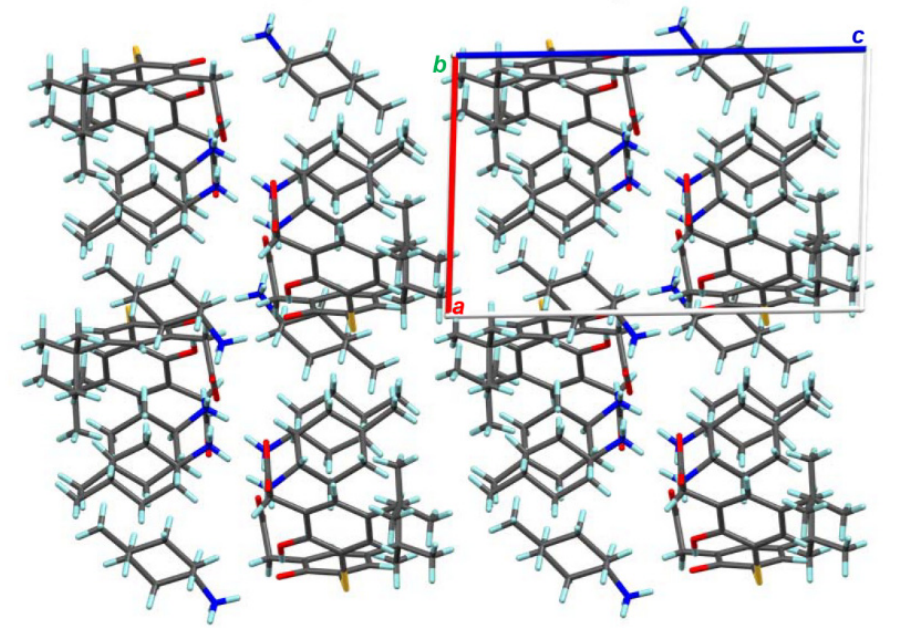

Figure S3. X-ray structure of 2.(trans-4-methylcyclohexanamine) $)_{3}$ : (a) a $1: 3$ salt between 2 and trans-4methylcyclohexanamine, (b) a 2:6 inclusion complex, (c) a parallel cross-section to the $a-b$ plane. and (d) a parallel cross-

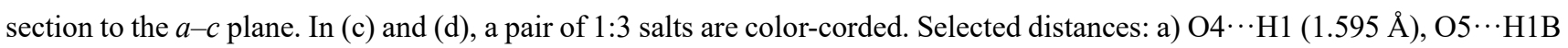
$(1.838 \AA), \mathrm{O} 3 \cdots \mathrm{H} 2 \mathrm{~A}(1.819 \AA), \mathrm{O} 4 \cdots \mathrm{H} 3 \mathrm{C}(1.821 \AA), \mathrm{O} 1 \cdots \mathrm{H} 33 \mathrm{~B}(2.535 \AA), \mathrm{O} 1 \cdots \mathrm{H} 1 \mathrm{C}(2.040 \AA), \mathrm{C} 10 \cdots \mathrm{H} 26 \mathrm{~A}(2.690 \AA)$,

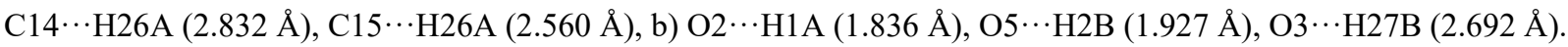




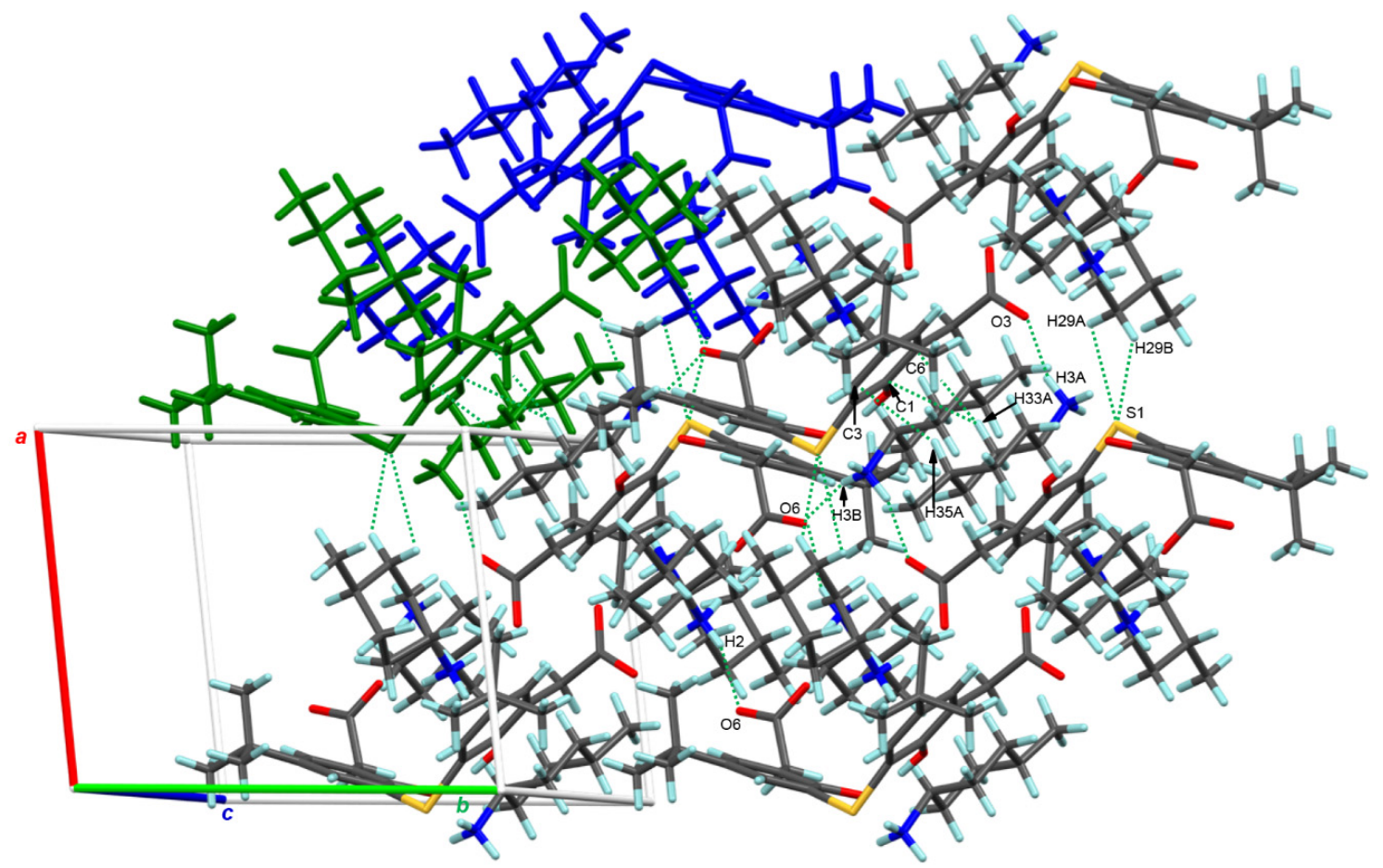

Figure S4. Expansion of Figure S3(c). Selected distances: O6 $\cdots \mathrm{H} 2(1.968 \AA)$, O6 $\cdots \mathrm{H} 3 \mathrm{~B}(1.946 \AA)$, O3 $\cdots \mathrm{H} 3 \mathrm{~A}(1.864 \AA)$, $\mathrm{C} 1 \cdots \mathrm{H} 33 \mathrm{~A}(2.869 \AA), \mathrm{C} 6 \cdots \mathrm{H} 33 \mathrm{~A}(2.747 \AA), \mathrm{C} 3 \cdots \mathrm{H} 35 \mathrm{~A}(2.801 \AA), \mathrm{S} 1 \cdots \mathrm{H} 29 \mathrm{~A}(2.988 \AA), \mathrm{S} 1 \cdots \mathrm{H} 29 \mathrm{~B}(2.928 \AA)$. 


\section{Crystallographic data for inclusion crystals}

Table S1. Crystallographic Data for the Inclusion Crystals of Diacid 2 with 3- and 4-Methylpyridine

\begin{tabular}{|c|c|c|}
\hline & 2.3-methylpyridine & $\mathbf{2} \cdot 4$-methylpyridine toluene $_{0.5}$ \\
\hline Empirical formula & $\mathrm{C}_{30} \mathrm{H}_{37} \mathrm{NO}_{6} \mathrm{~S}$ & $\mathrm{C}_{33.5} \mathrm{H}_{41} \mathrm{NO}_{6} \mathrm{~S}$ \\
\hline Formula weight & 539.66 & 585.73 \\
\hline Crystal system & triclinic & monoclinic \\
\hline Space group & $P \overline{1}$ & $P 2_{1} / c$ \\
\hline$a, b, c / \AA$ & $9.637(3), 9.748(4), 16.361(6)$ & $19.389(4), 15.669(3), 10.438(2)$ \\
\hline$\alpha, \beta, \gamma /^{\circ}$ & $86.333(5), 75.287(5), 69.792(5)$ & $90,101.635(3), 90$ \\
\hline$V / \AA^{3}$ & $1394.6(9)$ & $3106.2(10)$ \\
\hline Z & 2 & 4 \\
\hline $\mathrm{F}(000)$ & 576 & 1252 \\
\hline$T / \mathrm{K}$ & $100(2)$ & $100(2)$ \\
\hline$\rho_{\text {calc }} / \mathrm{gcm}^{-3}$ & 1.285 & 1.253 \\
\hline Reflections collected & 8065 & 17673 \\
\hline $\begin{array}{l}\text { Independent } \\
\text { reflections }\end{array}$ & $6113\left[R_{\text {int }}=0.0453\right]$ & $7075\left[R_{\text {int }}=0.0701\right]$ \\
\hline$\mu(\mathrm{Mo} \mathrm{K} \alpha) / \mathrm{mm}^{-1}$ & 0.160 & 0.149 \\
\hline $\begin{array}{l}\text { Data / restraints / } \\
\text { parameters }\end{array}$ & $6113 / 4 / 359$ & $7075 / 200 / 437$ \\
\hline$R_{1}, w R_{2}(I>2 \sigma(I))$ & $0.0737,0.1617$ & $0.0577,0.1063$ \\
\hline$R_{1}, w R_{2}$ (all data) & $0.1570,0.2164$ & $0.1222,0.1321$ \\
\hline Goodness-of-fit on $F^{2}$ & 1.010 & 1.010 \\
\hline $\begin{array}{l}\text { Largest diff. peak and } \\
\text { hole } / \mathrm{e} \cdot \AA^{3}\end{array}$ & 0.420 and -0.396 & 0.421 and -0.369 \\
\hline
\end{tabular}


Table S2. Crystallographic Data for the Inclusion Crystals of Diacid 2 with 2- and 6-Methylquinoline.

\begin{tabular}{|c|c|c|c|}
\hline & 2-2-methylquinoline $\cdot$ toluene 0.5 & 2.6-methylquinoline toluene & 2.6-methylquinoline acetonitrile \\
\hline Empirical formula & $\mathrm{C}_{75} \mathrm{H}_{36} \mathrm{~N}_{2} \mathrm{O}_{12} \mathrm{~S}_{2}$ & $\mathrm{C}_{41} \mathrm{H}_{47} \mathrm{NO}_{6} \mathrm{~S}$ & $\mathrm{C}_{36} \mathrm{H}_{42} \mathrm{~N}_{2} \mathrm{O}_{6} \mathrm{~S}$ \\
\hline Formula weight & 1271.57 & 681.85 & 630.77 \\
\hline Crystal system & triclinic & triclinic & triclinic \\
\hline Space group & $P \overline{1}$ & $P \overline{1}$ & $P \overline{1}$ \\
\hline$a, b, c / \AA$ & $19.965(3), 13.086(3), 23.497(5)$ & $\begin{array}{l}11.4571(16), 12.8125(18), \\
14.789(2)\end{array}$ & $9.589(3), 12.356(3), 15.066(4)$ \\
\hline$\alpha, \beta, \gamma /^{\circ}$ & $\begin{array}{l}92.721(3), 93.698(3), \\
110.195(3)\end{array}$ & $\begin{array}{l}72.1642(17), 67.7107(16) \\
71.2796(17)\end{array}$ & $104.914(4), 101.789(4), 92.677(4)$ \\
\hline$V / \AA^{3}$ & $3435.9(12)$ & $1859.8(4)$ & $1679.2(8)$ \\
\hline Z & 2 & 2 & 2 \\
\hline $\mathrm{F}(000)$ & 1356 & 728 & 672 \\
\hline$T / \mathrm{K}$ & $100(2)$ & $100(2)$ & $100(2)$ \\
\hline$\rho_{\text {calc }} / \mathrm{gcm}^{-3}$ & 1.229 & 1.218 & 1.248 \\
\hline Reflections collected & 19775 & 10683 & 9667 \\
\hline $\begin{array}{l}\text { Independent } \\
\text { reflections }\end{array}$ & $15022\left[R_{\mathrm{int}}=0.0186\right]$ & $8094\left[R_{\text {int }}=0.0160\right]$ & $7324\left[R_{\mathrm{int}}=0.0282\right]$ \\
\hline$\mu(\mathrm{Mo} \mathrm{K} \alpha) / \mathrm{mm}^{-1}$ & 0.140 & 0.134 & 0.144 \\
\hline $\begin{array}{l}\text { Data / restraints / } \\
\text { parameters }\end{array}$ & $15022 / 219 / 933$ & 8094 / 262 / 500 & 7324 / 4 / 423 \\
\hline$R_{1}, w R_{2}(I>2 \sigma(I))$ & $0.0637,0.1524$ & $0.0410,0.1042$ & $0.0569,0.1282$ \\
\hline$R_{1}, w R_{2}$ (all data) & $0.0900,0.1717$ & $0.0486,0.1104$ & $0.0908,0.1491$ \\
\hline Goodness-of-fit on $F^{2}$ & 1.030 & 1.029 & 1.019 \\
\hline $\begin{array}{l}\text { Largest diff. peak and } \\
\text { hole / } e \cdot \AA^{3}\end{array}$ & 1.369 and -0.481 & 0.326 and -0.343 & 0.575 and -0.558 \\
\hline
\end{tabular}


Table S3. Crystallographic Data for the Inclusion Crystals of Diacid 2 and Monoester 3 with 4Methylcyclohexanamine

\begin{tabular}{|c|c|c|}
\hline & 2.(trans-4-methylcyclohexanamine $)_{3}$ & 3.trans-4-methylcyclohexanamine \\
\hline Empirical formula & $\mathrm{C}_{45} \mathrm{H}_{75} \mathrm{~N}_{3} \mathrm{O}_{6} \mathrm{~S}$ & $\mathrm{C}_{68} \mathrm{H}_{102} \mathrm{~N}_{2} \mathrm{O}_{12} \mathrm{~S}_{2}$ \\
\hline Formula weight & 786.14 & 1203.62 \\
\hline Crystal system & triclinic & triclinic \\
\hline Space group & $P \overline{1}$ & $P \overline{1}$ \\
\hline$a, b, c / \AA$ & $10.1308(15), 14.411(2), 16.965(2)$ & $12.3387(19), 15.126(2), 18.749(3)$ \\
\hline$\alpha, \beta, \gamma /^{\circ}$ & $109.550(2), 90.174(2), 96.343(2)$ & $\begin{array}{l}100.1088(19), 103.8252(19) \\
90.740(2)\end{array}$ \\
\hline$V / \AA^{3}$ & $2317.8(6)$ & $3339.7(9)$ \\
\hline Z & 2 & 2 \\
\hline $\mathrm{F}(000)$ & 860 & 1304 \\
\hline$T / \mathrm{K}$ & $100(2)$ & $100(2)$ \\
\hline$\rho_{\text {calc }} / \mathrm{gcm}^{-3}$ & 1.126 & 1.197 \\
\hline Reflections collected & 26689 & 19329 \\
\hline $\begin{array}{l}\text { Independent } \\
\text { reflections }\end{array}$ & $10461\left[R_{\mathrm{int}}=0.0304\right]$ & $14615\left[R_{\mathrm{int}}=0.0189\right]$ \\
\hline$\mu(\mathrm{Mo} \mathrm{K} \alpha) / \mathrm{mm}^{-1}$ & 0.117 & 0.140 \\
\hline $\begin{array}{l}\text { Data / restraints / } \\
\text { parameters }\end{array}$ & $10461 / 613 / 716$ & $14615 / 73 / 820$ \\
\hline$R_{1}, w R_{2}(I>2 \sigma(I))$ & $0.0502,0.1254$ & $0.0639,0.1792$ \\
\hline$R_{1}, w R_{2}$ (all data) & $0.0738,0.1420$ & $0.0878,0.1992$ \\
\hline Goodness-of-fit on $F^{2}$ & 1.026 & 1.309 \\
\hline $\begin{array}{l}\text { Largest diff. peak and } \\
\text { hole / } e \cdot \AA^{3}\end{array}$ & 0.390 and -0.429 & 1.169 and -0.487 \\
\hline
\end{tabular}




\section{Thermal ellipsoid plots of inclusion crystals}

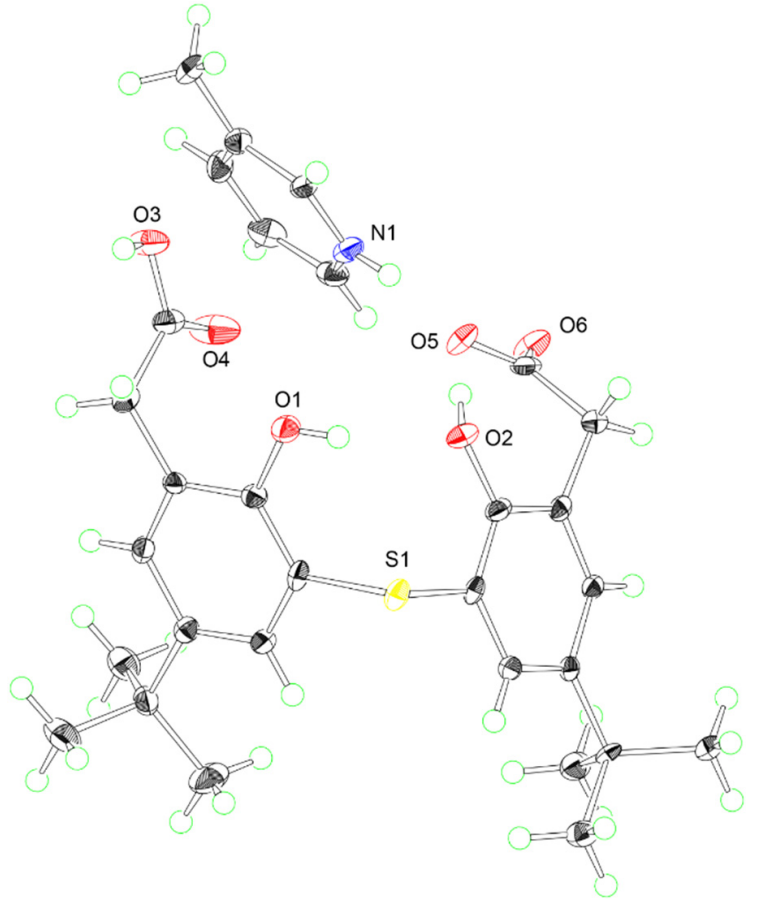

Figure S5. ORTEP drawing of 2·3-methylpyridine with 50\% probability ellipsoids (CCDC 2059346).
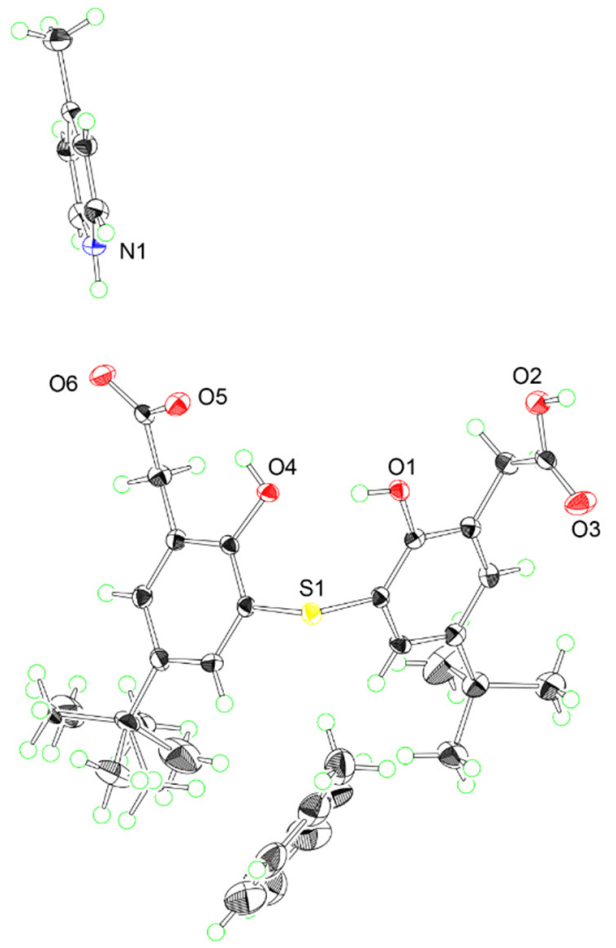

Figure S6. ORTEP drawing of 2-4-methylpyridine toluene 0.5 with $50 \%$ probability ellipsoids (CCDC 2059348). 


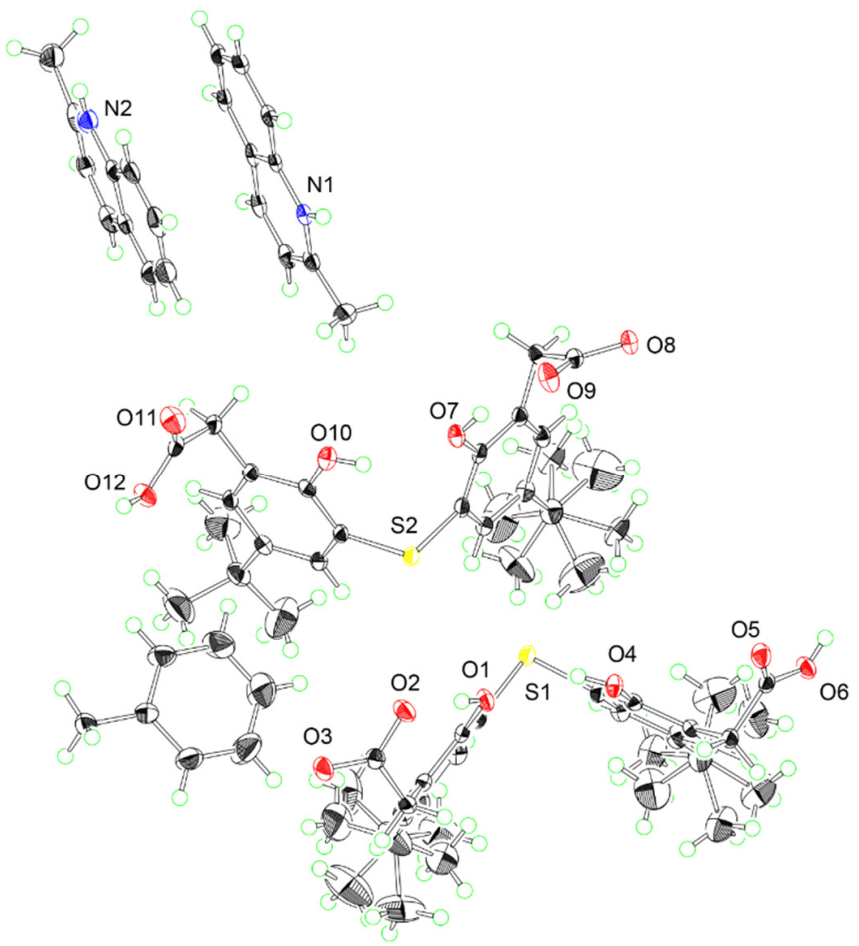

Figure S7. ORTEP drawing of 2-2-methylquinoline toluene 0.5 with $50 \%$ probability ellipsoids (CCDC 2059345).

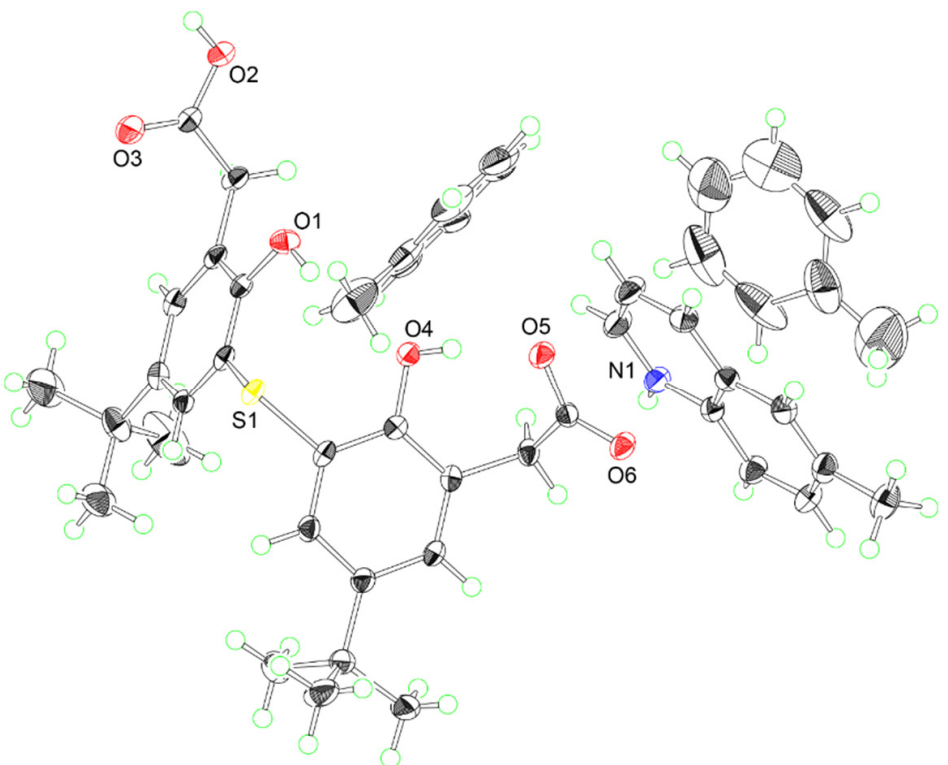

Figure S8. ORTEP drawing of 2.6-methylquinoline toluene with $50 \%$ probability ellipsoids (CCDC 2059350). 


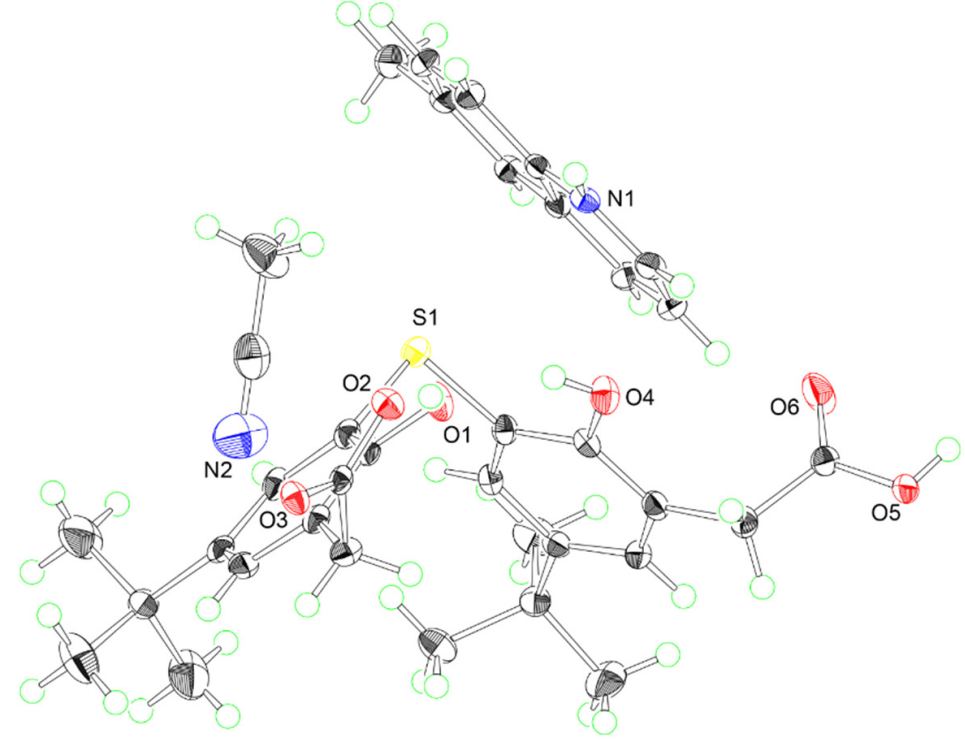

Figure S9. ORTEP drawing of 2.6-methylquinoline-acetonitrile with $50 \%$ probability ellipsoids (CCDC 2059349).

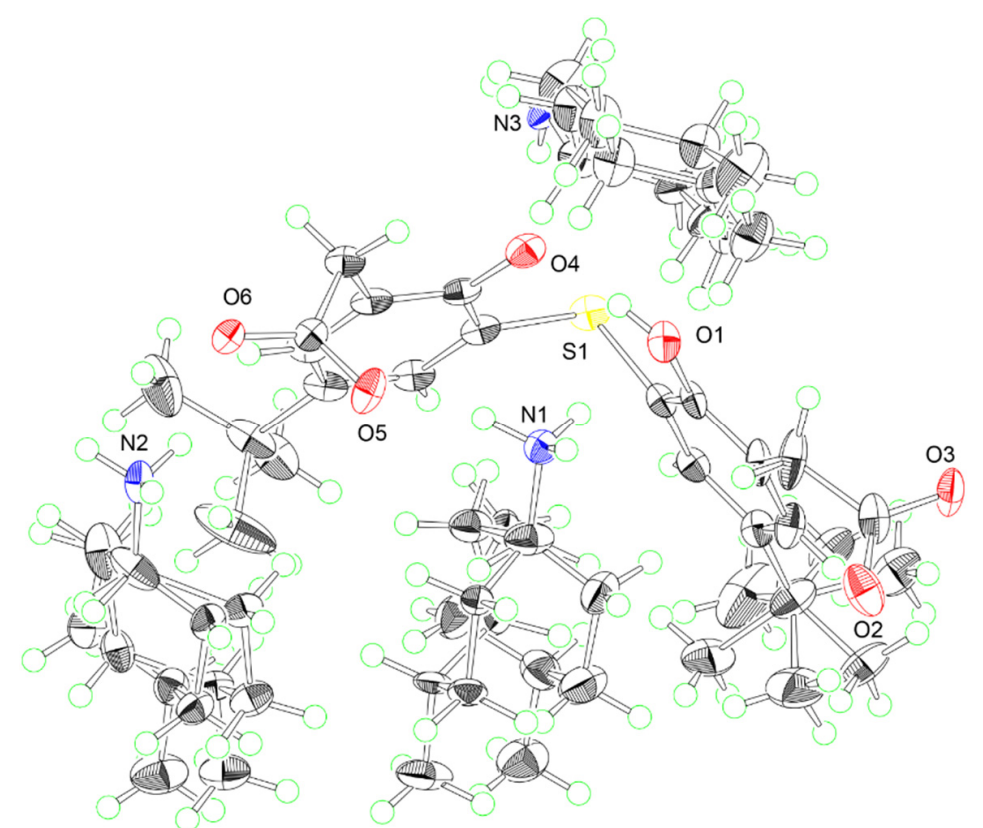

Figure S10. ORTEP drawing of 2.(trans-4-methylcyclohexanamine) $)_{3}$ with $50 \%$ probability ellipsoids (CCDC 2059347). 


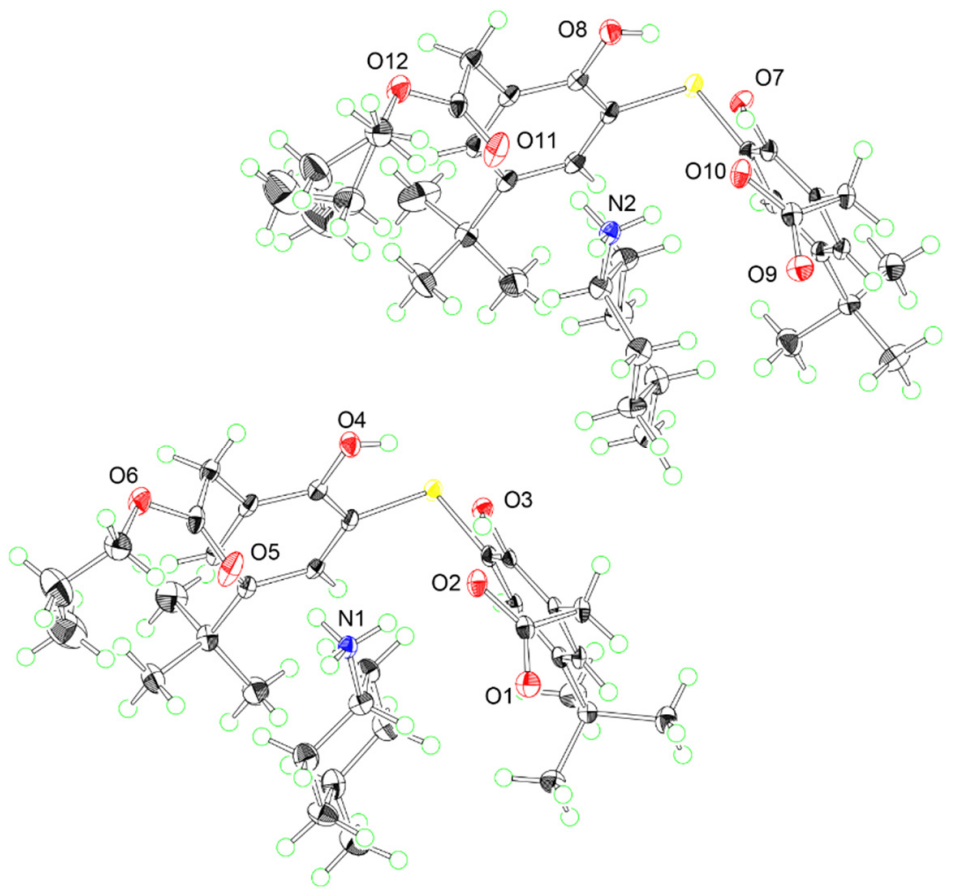

Figure S11. ORTEP drawing of 3-trans-4-methylcyclohexanamine with 50\% probability ellipsoids (CCDC 2059351). 